\title{
Association of serum 25-hydroxyvitamin D in COVID-19 : A study from India
}

\author{
Samala Naveenreddy' , Jaydip Ray Chaudhuri², Kandadai Rukmini Mridula ${ }^{3}$, Banda Balaraju', \\ VCS Srinivasarao Bandaru ${ }^{* 1,4}$ \\ 'Department of Medicine, Yashoda hospital Somajiguda Hyderabad-500082 India \\ ${ }^{2}$ Department of Neurology, Yashoda hospital Somajiguda Hyderabad-500082 India \\ ${ }^{3}$ Department of Neurology Nizam's Institution of Medical Sciences Panjagutta Hyderabad-500082 India \\ ${ }^{4}$ Department of Clinical Research Yashoda hospital Somajiguda Hyderabad-500082 India
}

ABSTRACT

\section{BACKGROUND}

Novel coronavirus infection 2019 (COVID-19), a pandemic has affected patients irrespective of gender and age. Existing studies have incriminated low levels of serum 25-hydroxyvitamin D to be associated with COVID-19 infection. The present study was to investigate serum 25-hydroxyvitamin D levels in patients with COVID-19 infection.

\section{METHODS}

We recruited prospectively 175 consecutive COVID-19 patients from the Department of Medicine, Yashoda hospital Hyderabad during the study period from May 2020 to December 2020. We measured in all patients, serum levels of 25-hydroxyvitamin D, calcium, phosphorus, alkaline phosphatase, C-reactive protein (CRP), D-Dimer, interleukin-6, procalcitonin, and ferritin.

\section{RESULTS}

Out of 175 patients $122(69.7 \%)$ were men, mean age was $57.2 \pm 13.6$ years. Clinical symptoms were fever in $175(100 \%)$ dry cough in $110(62.8 \%)$, tiredness in $105(60 \%)$, shortness of breath in $94(53.7 \%)$, and mechanical ventilator support requirement at admission in $40(22.8 \%)$. Serum 25 -hydroxyvitamin D deficiency was noted in 108(61.7\%), CRP was positive in 119(68\%), abnormal D-dimer levels in 96(54.8\%), abnormal procalcitonin levels in 107(61.1\%) abnormal interleukin-6 levels in 98(56\%), abnormal serum ferritin levels in $106(60.5 \%)$ and overall mortality in $13(7.4 \%)$. Older age $(p=0.006)$ hypertension ( $p=0.02)$, diabetes ( $p=0.01)$, CRP positivity $(p<0.0001)$ and mortality $(p=0.03)$ were significantly associated with serum 25-hydroxyvitamin D deficiency in COVID-19 patients. Serum 25-hydroxyvitamin D deficiency and age >60 years were significant predictors of mortality with odds of 7.4 ; $(95 \% \mathrm{Cl}: 1.10-56.36)$ and 2.8 : (95\%Cl: 0.81-9.50) respectively.

\section{CONCLUSION}

In our study, serum 25-hydroxyvitamin D deficiency was seen in 61.1\%, low levels of serum 25-hydroxyvitamin D was independently associated with $>60$ years age group and mortality in COVID-19.

\section{KEY WORDS}

COVID-19, Vitamin D, CRP, D-dimer and Outcome

\section{BACKGROUND}

A novel coronavirus 2019 (COVID-19) infection, rapidly spread throughout the world, caused by the severe acute respiratory syndrome coronavirus-2 (SARS-CoV-2), frequently produces severe lower respiratory tract symptoms. ${ }^{1}$ Recent studies have established that crude mortality rates range from $5.6 \%$ to $15.2 \%$ worldwide and the risk of death was found to be higher for elderly patients due to comorbid conditions like hypertension, diabetes mellitus, chronic kidney disease, asthma, cerebrovascular and cardiovascular diseases. ${ }^{2}$ The existing knowledge gap on the human immune response to COVID-19 is a critical barrier for treating the disease; however, potential immunemodulators may help alleviate the severity and improve outcomes. ${ }^{3}$ Recent studies have shown that vitamin D

\section{*Corresponding Author}

Dr.VCS Srinivasarao Bandaru, Ph. D

Department of Medicine \& Clinical Research

Yashoda hospitals Hyderabad -82m, India

Email:rsbhandaru@gmail.com

Mobile number:919441266519; Fax number:914067776666

ORCID ID: 0000-0001-6783-5289 
deficient subjects are more prone to COVID-19 infection. 1 .

Vitamin $D$ is important for human body, modulation of immune function and maintaining a balance between calcium and phosphorus, ${ }^{4}$ its active forms being vitamin D3 or serum 25-hydroxyvitamin D (cholecalciferol) and vitamin D2 (ergocalciferol). ${ }^{5}$ Vitamin D deficiency causes weakness, reduced bone mineralization, increase in inflammation and neurological diseases. ${ }^{6,7}$ We aim to investigate association of serum 25-hydroxyvitamin D in COVID-19 in Indian patients. On this topic, very few studies are available from the Indian sub-continent.

\section{METHODS}

We prospectively recruited 225 patients, who presented with cough, tiredness, fever, dyspnoea, etc., with a primary presumptive diagnosis of COVID-19, and were admitted in the Department of Medicine at Yashoda Hospital. Yashoda hospital is a teaching hospital for postgraduate students. Out of 225 patients, 50 patients had negative real-time reverse transcriptase-PCR (RT-PCR) assay for COVID-19, these patients were removed from the study and remaining 175 patients were included in the study. The study was from May 2020 to December 2020. The study was approved by the institutional ethics committee and informed consent was taken from all the patients.

COVID-19 was confirmed by RT-PCR, currently the gold standard, approved by the Indian Council of Medical Research (ICMR) New Delhi.8 RT-PCR negative patients who had clinical presentation compatible with COVID-19, patients who were not admitted and were managed on OP basis, patients who already were known to have Vitamin D deficiency, hypoparathyroidism, and pediatric patients were excluded from the study.

At the time of admission all COVID-19 patients, underwent detailed laboratory investigations including complete blood picture, liver function tests, urine analysis (including urine albumin), levels of serum creatinine, blood urea, serum albumin, serum glucose, serum C-Reactive Protein (CRP), serum interleukin-6, serum procalcitonin, serum D-dimer, serum ferritin, serum calcium, serum phosphorus and serum alkaline phosphatase. Computed tomography (CT) scan chest was done in all.

\section{Risk factors Assessment}

Hypertension was defined as a systolic blood pressure $>140 \mathrm{~mm} \mathrm{Hg}$ and/or a diastolic blood pressure > $90 \mathrm{~mm} \mathrm{Hg}$ based on the average of two blood pressure measurements or a patient's has taking anti-hypertension medication. Diabetes mellitus was diagnosed if the fasting glucose levels more than $110 \mathrm{mg} / \mathrm{dL}$ or the patient was on anti- diabetic medications. Alcoholics were defined as those in whom the alcohol consumption was more than $50 \mathrm{~g} /$ day (equivalent to $500 \mathrm{~mL}$ [2 drinks] of wine, $1000 \mathrm{~mL}$ of beer, or.5 drinks [units] of spirits). Smokers were defined as those reporting daily smoking. Ex-smokers and occasional smokers were classified as non-smokers. ${ }^{8,9}$ CRP levels $>10.1 \mathrm{mg} / \mathrm{l}$ were considered positive. ${ }^{10}$ In our laboratory, interleukin-6 (IL-6) $>6.5 \mathrm{pg} / \mathrm{ml}$, serum procalcitonin $>0.07$ $\mathrm{ng} / \mathrm{ml}$, D-dimer $>501 \mathrm{ng} / \mathrm{ml}$, serum ferritin $>405 \mathrm{ng} / \mathrm{ml}$ were considered abnormal. ${ }^{8}$

\section{Estimation of serum 25-hydroxyvitamin D}

In our lab, chemiluminescent micro-particle immunoassay (CMIA) with automated instruments were used for analysis of 25-hydroxyvitamin $\mathrm{D}$, values $\leq 19.9 \mathrm{ng} / \mathrm{mL}$ were diagnosed as 25-hydroxyvitamin D deficiency and $\geq 20.0$ $\mathrm{ng} / \mathrm{ml}$ values were considered normal. ${ }^{11-13}$

\section{Statistical analysis}

Statistical analysis was performed using Statistical Package for Social Sciences (SPSS) 17.0 window software (SPSS Inc Chicago, Illinois (IL) 60606 USA). Continuous variables were presented in titers of mean and $\pm S D$. Categorical variables were used as proportions and chi-square test was done to study the association in proportions. We estimated the odds ratio $(\mathrm{OR})$ and the resulting $95 \% \mathrm{Cl}$ for the matched good and poor outcome pairs. All tests were two-sided done and $p$-value $\leq$ of 0.05 was considered statistically significant.

\section{RESULTS}

A total of 175 patients with COVID-19 were included. Men were $122(69.7 \%)$ and women were $53(30.2 \%)$ with a mean age $57.2 \pm 13.6$ years (age range from 24 to 82 years). Mean hospital stay was for13.0 \pm 6.7 days (range from 10-32 days). Assessing for comorbidities, 56(32\%) were hypertensive, 26(14.8\%) had diabetes mellitus while 31(17.7\%) were smokers.

Fever, dry cough, tiredness, and shortness of breath were the most common clinical symptoms found in 175(100\%), $110(62.8 \%), 105(60 \%)$, and 94(53.7\%) patients, respectively (Table -1 ). Forty patients $(22.8 \%)$ required mechanical ventilator support at admission.

Serum 25-hydroxyvitamin D deficiency was seen in $108(61.7 \%)$ patients, CRP positivity was present in 119(68\%), abnormal D-dimer levels in 96(54.8\%), abnormal procalcitonin levels in 107(61.1\%), abnormal interleukin-6 levels in 98(56\%) and abnormal ferritin levels in 106(60.5\%) patients. 


\section{Table1: Baseline characteristics}

\begin{tabular}{|c|c|}
\hline Parameters & Number $(n=175)$ \\
\hline Men & $122(69.7 \%)$ \\
\hline Mean age in years & $57.2 \pm 13.6$ \\
\hline Age range in years & $24-82$ \\
\hline Young patients $(\leq 59$ years $)$ & $94(53.7 \%)$ \\
\hline Elder age patients ( $\geq 60$ years) & $81(46.2 \%)$ \\
\hline Hospital stay range in days & $10-32$ \\
\hline Mean Hospital stay in days & $13.0 \pm 6.7$ \\
\hline Serum 25-hydroxyvitamin D deficiency & $108(61.7 \%)$ \\
\hline Hypertension & $56(32 \%)$ \\
\hline Diabetes mellitus & $26(14.8 \%)$ \\
\hline Smokers & $31(17.7 \%)$ \\
\hline Alcoholics & $14(8 \%)$ \\
\hline Asthmatics & $20(11.4 \%)$ \\
\hline Previous history of cardiovascular disease & $22(12.5 \%)$ \\
\hline Previous history of cerebrovascular disease & $12(6.8 \%)$ \\
\hline History of any cancer & $11(6.2 \%)$ \\
\hline History of chronic kidney disease & $19(10.8 \%)$ \\
\hline \multicolumn{2}{|l|}{ Clinical symptoms } \\
\hline Fever & $175(100 \%)$ \\
\hline Dry cough & $110(62.8 \%)$ \\
\hline Tiredness & $105(60 \%)$ \\
\hline Shortness of breath & $94(53.7 \%)$ \\
\hline Mechanical ventilator Support & $40(22.8 \%)$ \\
\hline CRP positive $(>10.1 \mathrm{mg} / \mathrm{L})$ & $119(68 \%)$ \\
\hline Abnormal D-dimer $(>501)$ & $96(54.8 \%)$ \\
\hline Abnormal Procalcitonin & $107(61.1 \%)$ \\
\hline Abnormal interleukin -6 & $98(56 \%)$ \\
\hline Abnormal Serum Ferritin & $106(60.5 \%)$ \\
\hline Mean serum calcium (mg/dl) & $8.6 \pm 2.5$ \\
\hline Mean serum phosphorus (mg/dl) & $3.6 \pm 1.1$ \\
\hline Mean Alkaline phosphotase (U/L) & $119.9 \pm 23.8$ \\
\hline Mortality & $13(7.4 \%)$ \\
\hline
\end{tabular}

Significant differences were found between deficiency of serum 25-hydroxyvitamin $D$ and normal serum 25 -hydroxyvitamin $D$ groups in variables of age $(p=0.006)$, presence of hypertension $(p=0.02)$, diabetes mellitus $(p=0.01)$, requirement of mechanical ventilator support at admission ( $p=0.01)$, CRP positivity $(p<0.0001)$ and mortality $(p=0.02)$ (Table 2).
Table 2: Different serum 25-hydroxy vitamin

\section{D deficiency and normal with COVID-19}

\begin{tabular}{|c|c|c|c|}
\hline Parameters & $\begin{array}{l}\text { 25-hydroxy } \\
\text { vitamin D } \\
\text { deficiency } \\
(\mathrm{n}=108)\end{array}$ & $\begin{array}{l}\text { 25-hydroxy } \\
\text { vitamin } \\
\text { D normal } \\
(n=67)\end{array}$ & $\mathrm{p}$ value \\
\hline Men & $77(71.2 \%)$ & $45(67.1 \%)$ & 0.4 \\
\hline Mean age years & $61.5 \pm 14.2$ & $54.3 \pm .13 .2$ & $=0.006$ \\
\hline$\geq 60$ years & $59(54.6 \%)$ & $22(32.8 \%)$ & 0.01 \\
\hline $\begin{array}{l}\text { Hospital stay duration } \\
\text { range days }\end{array}$ & $10-31$ & $9-29$ & NA \\
\hline $\begin{array}{l}\text { Mean duration } \\
\text { of hospital }\end{array}$ & $13.3 \pm 6.6$ & $13.0 \pm 6.0$ & 0.7 \\
\hline Fever & $108(100 \%)$ & $67(100 \%)$ & 0.9 \\
\hline Dry cough & $70(64.4 \%)$ & $40(59.7 \%)$ & 0.1 \\
\hline Tiredness & $60(55.5 \%)$ & $45(67.1 \%)$ & 0.3 \\
\hline shortness of breath & $52(48.1 \%)$ & $43(64.1 \%)$ & 0.4 \\
\hline Hypertension & $42(38.8 \%)$ & $14(20.8 \%)$ & 0.02 \\
\hline Diabetes mellitus & $22(20.3 \%)$ & $4(5.9 \%)$ & 0.01 \\
\hline Smoker & $15(8.5 \%)$ & $16(23.8 \%)$ & 0.1 \\
\hline Alcoholics & $7(4 \%)$ & $7(10.4 \%)$ & 0.5 \\
\hline Asthmatics & $13(7.4 \%)$ & $6(8.9 \%)$ & 0.6 \\
\hline $\begin{array}{l}\text { Previous history of } \\
\text { coronary artery disease }\end{array}$ & $15(8.5 \%)$ & $7(10.4 / 5)$ & 0.6 \\
\hline $\begin{array}{l}\text { Previous history of } \\
\text { cerebrovascular disease }\end{array}$ & $4(2.2 \%)$ & $8(11.9 \%)$ & 0.07 \\
\hline History of any cancer & $5(4.6 \%)$ & $6(8.9 \%)$ & 0.9 \\
\hline $\begin{array}{l}\text { History of Chronic kidney } \\
\text { Disease }\end{array}$ & $13(19.4 \%)$ & $6(8.9 \%)$ & 0.9 \\
\hline $\begin{array}{l}\text { Mechanical ventilator } \\
\text { support }\end{array}$ & $32(29.6 \%)$ & $8(11.9 \%)$ & 0.01 \\
\hline CRP positivity & $95(87.9 \%)$ & $24(35.8 \%)$ & $<0.0001$ \\
\hline $\begin{array}{l}\text { Abnormal D-dimer values } \\
(\mathrm{ng} / \mathrm{ml})\end{array}$ & $60(55.5 \%)$ & $36(53.7 \%)$ & 0.9 \\
\hline $\begin{array}{l}\text { Abnormal Procalcitonin } \\
\text { levels }\end{array}$ & $73(67.5 \%)$ & $41(61.1 \%)$ & 0.4 \\
\hline $\begin{array}{l}\text { Abnormal Interleukin -6 } \\
\text { levels }\end{array}$ & $60(55.5 \%)$ & $38(56.7 \%)$ & 0.9 \\
\hline $\begin{array}{l}\text { Abnormal serum Ferritin } \\
\text { levels }\end{array}$ & $65(60.1 \%)$ & $40(59.7 \%)$ & 0.9 \\
\hline Mean serum calcium $(\mathrm{mg} / \mathrm{dl})$ & $8.4 \pm 2.1$ & $8.6 \pm 2.4$ & 0.5 \\
\hline
\end{tabular}




\begin{tabular}{|l|l|l|l|}
\hline $\begin{array}{l}\text { Mean serum phosphorus } \\
(\mathrm{mg} / \mathrm{dl})\end{array}$ & $3.4 \pm 1.4$ & $3.7 \pm 0.9$ & 0.1 \\
\hline $\begin{array}{l}\text { Mean Alkaline phosphotase } \\
(\mathrm{U} / \mathrm{L})\end{array}$ & $120.1 \pm 31.4$ & $117.4 \pm 25.4$ & 0.5 \\
\hline Mortality & $12(11.1 \%)$ & $1(1.4 \%)$ & 0.02 \\
\hline
\end{tabular}

7.93) and CRP positivity (odds: 1.01;95\% Cl: 0.09-2.01) were the predictors detected.

Table 4: Predictors of mortality in COVID-19

When patients who succumbed to COVID-19 were compared to those who recovered, more than 60 years of age $(p=0.05)$, hypertension $(p=0.01)$, and deficiency of serum 25-hydroxyvitamin D $(p=0.03)$ were significantly associated with mortality. (table 3 ).

\section{Table 3: Comparison between deaths and}

\section{survivors in COVID-19}

\begin{tabular}{|l|l|l|l|}
\hline Parameters & Deaths & Survivors & p value \\
& $(\mathbf{n = 1 3 )}$ & $\mathbf{( n = 1 6 2 )}$ & \\
\hline Men & $8(61.5 \%)$ & $114(70.3 \%)$ & 0.08 \\
\hline Women & $5(38.4 \%)$ & $48(29.6 \%)$ & 0.5 \\
\hline Mean age & $58.2 \pm 11.5$ & $57.06 \pm 13.2$ & 0.7 \\
\hline$>60$ years & $10(76.9 \%)$ & $71(43.8 \%)$ & 0.05 \\
\hline Hypertension & $1(7.6 \%)$ & $55(33.9 \%)$ & 0.01 \\
\hline Diabetes mellitus & $3(23 \%)$ & $23(14.1 \%)$ & 0.08 \\
\hline $\begin{array}{l}\text { Previous history of coronary artery } \\
\text { disease }\end{array}$ & 0 & $22(13.5 \%)$ & 0.3 \\
\hline Smoking & & & \\
\hline Alcoholics & $1(7.6 \%)$ & $30(18.5 \%)$ & 0.5 \\
\hline Asthma & $1(7.6 \%)$ & $13(8 \%)$ & 0.6 \\
\hline Mechanical ventilator support & $1(7.6 \%)$ & $18(11.1 \%)$ & 0.9 \\
\hline History of Chronic kidney disease & $8(61.5 \%)$ & $32(19.7 \%)$ & $<0.0001$ \\
\hline Serum 25-hydroxyvitamin D deficiency & $2(15.3 \%)$ & $17(10.4 \%)$ & 0.9 \\
\hline Previous history of cerebrovascular & $1(7.6 \%)$ & $11(6.7 \%)$ & 0.6 \\
\hline disease & & & 0.03 \\
\hline History of any cancer & $1(7.6 \%)$ & $10(6.1 \%)$ & 0.7 \\
\hline CRP positivity & $9(69.2 \%)$ & $110(67.9 \%)$ & 0.8 \\
\hline Abnormal D-dimer values (ng/ml) & $6(46.1 \%)$ & $90(55.5 \%)$ & 0.6 \\
\hline Abnormal Procalcitonin levels & $7(53.8 \%)$ & $99(61.1 \%)$ & 0.8 \\
\hline Abnormal Interleukin -6 levels & $11(84.6 \%)$ & $87(53.7 \%)$ & 0.05 \\
\hline Abnormal serum Ferritin levels & $7(53.8 \%)$ & $100(61.7 \%)$ & 0.7 \\
\hline & & & \\
\hline
\end{tabular}

On further analysing the predictors of mortality (table 4), deficiency of serum 25-hydroxyvitamin D (odds: $7.48 ; 95 \% \mathrm{Cl}$ : 1.10-56.3), >60 years of age (odds: $2.81 ; 95 \% \mathrm{Cl}: 0.81-9.50)$, diabetes mellitus (odds: 1.8;95\% Cl: 0.46-7.08), mechanical ventilator support at admission (odds: 0.95;95\% Cl: 0.11-

\begin{tabular}{|l|l|l|l|}
\hline Parameters & Odds ratio & $\mathbf{9 5 \%}$ CI & $\begin{array}{l}\text { p } \\
\text { value }\end{array}$ \\
\hline Men & 0.61 & $0.21-2.1$ & 0.08 \\
\hline$>60$ years & 2.81 & $1.81-9.50$ & 0.1 \\
\hline Abnormal Interleukin -6 levels & 0.1 & $0.02-1.21$ & 0.3 \\
\hline Diabetes mellitus & 1.8 & $0.46-7.08$ & 0.7 \\
\hline $\begin{array}{l}\text { Mechanical ventilator support at } \\
\text { admission time }\end{array}$ & 0.95 & $0.11-7.93$ & 0.6 \\
\hline $\begin{array}{l}\text { Serum 25-hydroxyvitamin D } \\
\text { deficiency }\end{array}$ & 7.48 & $1.10-$ & 0.05 \\
\hline CRP positive & & 56.3 & \\
\hline
\end{tabular}

\section{DISCUSSION}

In our study, from Indian subcontinent, $61.7 \%$ of patients with COVID-19 had serum 25-hydroxyvitamin D deficiency, which is in agreement with previous reports from developed countries like Spain 82.2\%, ${ }^{14}$ Turkey $69.1 \%,{ }^{15}$ Iran 67.2\%, ${ }^{16}$ UK $55.7 \%,{ }^{17}$ USA $40 \% .{ }^{18}$ Ekiz et al, showed in his study that high levels of vitamin D conferred lower risk of COVID-19. ${ }^{19}$ Randomized controlled trials have found that subjects taking vitamin $\mathrm{D}$ supplementation reduced the risk of influenza infection. ${ }^{20}$ Similarly vitamin D deficiency was found to increase risk of COVID-19 by an odds ratio of 1.45 (95\%Cl:1.08-1.95). ${ }^{21}$ However few studies have noted no significant association between vitamin D deficiency and COVID-19. ${ }^{22}$

Previous studies have shown that many risk factors can lead to vitamin D deficiency, like low sun exposure, obesity, being male, dyslipidemia, increased skin thickness. ${ }^{1,5,7}$ Recent studies have incriminated increasing age as a causative factor for decreasing vitamin D levels. ${ }^{23}$

Most of the studies have found a higher prevalence of vitamin D deficiency among older people, due to the lower skin capacity in older people to produce vitamin D after sun exposure or lack of vitamin D intake, ${ }^{24}$ although some studies have reported to the different. ${ }^{25}$

In our study, we noted that age $>60$ years was significantly associated with serum 25-hydroxy vitamin D deficiency even in patients with COVID-19 ( $p=0.01)$, our findings are supported by others. ${ }^{21,26}$ This confirms the association between increasing age and vitamin D deficiency.

We also noted that hypertension was significantly 
associated with serum 25-hydroxyvitamin D deficiency in patients with COVID-19 ( $p=0.02)$, these findings were advocated by previous studies. ${ }^{26}$ A prior study from India demonstrated that serum 25-hydroxyvitamin D deficiency was significantly associated with primary hypertension in general population. ${ }^{11}$ In our study, in this cohort of COVID 19 patients, showed hypertension was significantly higher among patients with 25-hydroxy vitamin D deficiency, Biesalski et al, showed in his study a strong association with an odds ratio of 4.48; 95\%Cl:3.69-5.45. ${ }^{26}$ However few studies have noted no significant association between hypertension and COVID-19.20

Diabetes is one of the major risk factors for infections and vitamin D deficiency is significantly associated with diabetes mellitus. ${ }^{6}$ In the current study, we found serum 25-hydroxyvitamin D deficiency was significantly associated with diabetes in COVID-19 patients $(p=0.01)$, these findings were advocated by others. ${ }^{20,26}$

In our study, we established serum 25-hydroxyvitamin D deficiency was not significantly associated with smoking and consumption of alcoholic, these findings noted by others. $^{27}$

CRP is produced by the hepatocytes in the liver and higher CRP levels are a marker for infections. It is a nonspecific marker and is elevated via the bioactivity of cytokines like interleukin-6. ${ }^{28}$ Daneshkhah et al, proposed that vitamin $\mathrm{D}$ deficiency causes an increase in the CRP levels due to cytokine storm. ${ }^{29}$ Some Indian studies have shown elevated CRP levels were significantly associated with serum 25-hydroxyvitamin D deficiency in normal people. 5,6,13

In our study, we noted CRP positivity were higher among COVID 19 patients with serum 25-hydroxyvitamin D deficiency $(p<0.0001)$ compared to those with normal serum 25-hydroxyvitamin D, our findings were advocated by others. ${ }^{16,28}$ Recent studies have proposed that CRP is released with other pro-inflammatory cytokines and may have a pathogenetic role in modulation of inflammation and cytokine storm in COVID-19 patients, thus low levels of vitamin D by influencing CRP might enhance the cytokine storm in COVID-19 patients and may increase the risk of severity and mortality. ${ }^{17}$ However few studies have shown no significant association between serum 25-hydroxyvitamin D deficiency and elevated CRP levels in COVID-19 affected patients. ${ }^{15}$

In the current study, we noted no significant association between serum 25-hydroxy vitamin D deficiency and elevated D dimer levels in COVID-19, these findings are supported by others. ${ }^{30}$ However, few studies have shown a significant association between abnormal $\mathrm{D}$ dimer levels and vitamin D deficiency in COVID-19.17

We did not find any association between serum 25-hydroxy vitamin D deficiency and abnormal interleukin-6 levels in COVID-19 patients, these finding supported by other.15 while contrasted by few others. ${ }^{30}$

In our study, there was no significant association of abnormal serum procalcitonin with 25-hydroxyvitamin D deficiency, few other studies have shown significant association. ${ }^{17}$ We also did not find any significant association between abnormal serum ferritin levels and serum 25-hydroxyvitamin D deficiency in COVID-19, these findings are advocated by others. ${ }^{31}$ However, some studies have established that elevated serum ferritin levels were significantly associated with vitamin D deficiency in COVID-19.28,29

In the current study, we established a significant association between mechanical ventilator support at admission and serum 25-hydroxyvitamin D deficiency in COVID-19 $(p=0.01)$, these findings were noted by others. ${ }^{31}$ However, Szeto et al, noted no significant association between vitamin $\mathrm{D}$ deficiency and mechanical ventilator support in COVID-19 patients. $^{32}$

Studies have shown COVID-19 mortality rate was different in various countries and ranges from 5-25\%.9 Recent studies have shown, less mortality in India compared to the western world. ${ }^{33}$ In our study, the overall mortality was $6.2 \%$ some other studies have shown similar findings. ${ }^{34}$ In the current study, we found serum 25-hydroxyvitamin D deficiency was significantly associated with mortality in COVID-19 $(p=0.02)$, our findings were advocated by others. ${ }^{14,15}$ Karhan et al showed in their study vitamin $D$ deficiency was noted in $92.8 \%$ of patients who died..$^{15}$ Hermandez et al, noted in his study, mortality was $10.4 \%$ of those with Vitamin D deficiency. ${ }^{14}$ Recent studies have found around $70 \%$ of COVID-19 deaths in African American individuals had concomitant vitamin D deficiency. ${ }^{3}$ Retrospective multicentric studies have observed that vitamin D deficiency with CVOID-19 patients had poor outcomes while those with high levels of vitamin D had good outcomes. ${ }^{35}$

Vitamin D deficiency increases the $X$ chromosome-linked "Renin-Angiotensin" System (RAS) activity, making men more susceptible to ACE2 receptor deregulation and theoretically, to increased COVID-19 morbidity. ${ }^{36}$ Even though vitamin $D$ deficiency is not universal in severe COVID-19, every deleterious symptom can be explained by RAS over-reaction, which would occur more easily in individuals without sufficient vitamin D to control the RAS. ${ }^{37}$

In our study, we noted serum 25-hydroxyvitamin D deficiency had an independent predictive value for mortality (odds; 7.48 ; 95\% Cl:1.10- 56.3) similar findings noted by Raharusun 
et al, he found an odds ratio of 19.1 between vitamin D deficiency and mortality ${ }^{36}$ and in concordance Karhan et al showed that increased vitamin D levels were associated with decreased risk of mortality (odds;0.927;95\% $\mathrm{Cl}$ : 0.875 - 0.982). ${ }^{15}$ However few studies have shown no significant association between vitamin D deficiency and mortality in COVID-19. ${ }^{22}$

Studies have found that increasing age also is one of the major risk factors for poor outcome in COVID-19;38 in our study, we also established increasing age as a predictor of mortality in COVID-19 (Odds: 2.81;95\%Cl:1.81-9.50).

Our study showed no significant association of hypertension with mortality, similar to diabetes mellitus, these findings advocated by others. ${ }^{20}$ However few studies have noted a significant association between hypertension and diabetes mellitus with mortality. ${ }^{26}$

In the current study we noted abnormal interleukin-6 levels were significantly associated with mortality, and poor outcome caused by cytokine storm, our findings were supported by others. ${ }^{30}$ Our study suggests that vitamin D deficiency seems to play a major role in mortality due to its impact on pathways other than that related to interleukin-6 and has an additive effect.

Strength of our study was that all lab tests were performed in a single lab minimising inter rater variability, we were able to perform odds ratio and evaluate the predictors of mortality.

In our study, we established that serum25-hydroxyvitamin D deficiency was seen in $61.7 \%$ of patients with COVID-19 and is significantly associated with the infection. Age above 60 years and serum25-hydroxyvitamin D deficiency were independently associated with mortality. Further large-scale studies are required to confirm these findings. symptoms .

\section{Acknowledgment}

All authors are thankful to Dr. GS. Rao, Managing Director, Dr A. Lingaiah Director of Medical Services, Dr. G. Pavan, and Dr. G. Abhinav, Directors, Yashoda group of hospitals for their generous support to carry out this study at Yashoda Hospital Hyderabad.

Disclosures and conflict of Interest: All authors declared Nil

Author Contributions: Naveenreddy S: study concept and data collection, Chaudhuri JR: study design and manuscript review, Mridula KR: drafting of the manuscript and data analysis, Balaraju B: manuscript review and data collection, BandaruVCS: study concept and design data analysis, and drafting of the manuscript.

\section{REFERENCES}

1)Laird E, Rhodes J, Kenny RA. Vitamin D and Inflammation: Potential Implications for Severity of Covid-19.Ir Med J. 2020;113:81.

2)Yılmaz $K$, Şen V. Is vitamin D deficiency a risk factor for COVID 19 in children? Pediatric Pulmonology. 2020;55:35953601 .

3)Ebadi M, Montano-Loza Al Perspective: improving vitamin D status in the management of COVID-19 European Journal of Clinical Nutrition.2020;74:856-859.

4)Chaudhuri JR, Mridula KR, Alladi $S$, et al. Serum 25-hydroxyvitamin $\mathrm{D}$ deficiency in ischemic stroke and subtypes in Indian patients. Journal of stroke.2014;16:44-50.

5)Chaudhuri JR, Mridula KR, Anamika A, et al. Deficiency of 25-hydroxyvitamin D and Dysliipidemia in Indian Subjects. J Lipids. 2013;623420:7.

6)Chaudhuri JR, Mridula KR, Lingaiah A, et al. Association between 25-Hydroxyvitamin D and Type 2 Diabetes: A Case Control Study. Iranian J Diabetes and Obesity. 2014;6:4755.

7)Chaudhuri JR, Mridula KR, Kishore CR, et al. Association of 25-hydroxyvitamin D deficiency in pediatric epilepsy: A study from tertiary care center. Iranian Journal of Child Neurology.2017;11:48-56.

8)Lingaiah A, Srinivasarao Bandaru VCS. Role of Biomarker in COVID-19: A Study from Tertiary Care Center Ann Infect Dis Epidemiol.2021;6:1062.

9)Bandaru VCSS, Chaudhuri JR, Lalitha P, et al. Prevalence of asymptomatic Nonalcoholic Fatty Liver Disease in nondiabetes subjects: A study from South India Egypt j Internal medicine.2019;31:92-98.

10)Bandaru VCS, Kaul S, Boddu DB, et al. Hyperhomocystenemia, associated with Chlamydia pneumonia seropositivity in ischemic stroke. Neurol Asia.2009;14:1-5.

11)Kuchulakanti PK Chaudhuri RC, Annad U, et al. Association of serum 25-hydroxyvitamin D levels with primary hypertension: a study from south India. Hypertension Research.2020:2020 
12)Chaudhuri JR, Mridula KR, Umamahesh $U$, et al. Association of serum 25-hydroxyvitamin D in Multiple Sclerosis: A study from South India. Neurological Disorder and Stroke International.2018;1:1-6.

13)Chaudhuri JR, Mridula KR, Umamahesh $U$, et al. Association of 25-hydroxyvitamin $D$ and Carotid atherosclerosis in Indian population: A from South India. Ann Indian Acad Neurol.2017;20:242-247.

14)Hernandez, JL, Nan D, Fernandez-Ayala M, et al. Vitamin D Status in Hospitalized Patients with SARS-CoV-2 Infection. The Journal of Clinical Endocrinology \& Metabolism.2020; $\mathrm{XX}: 1-11$.

15)Karhan S. Katkat F Impact of serum $25(\mathrm{OH})$ vitamin $D$ level on mortality in patients with covid-19 in turkey. Nutr Health Aging. 2020:2020

16)Maghbooli Z, Sahraian MA, Ebrahimi M, et al. Vitamin D sufficiency, a serum 25-hydroxyvitamin D at least $30 \mathrm{ng} / \mathrm{mL}$ reduced risk for adverse clinical outcomes in patients with COVID-19 infection. PLoS ONE.2020; 15:e0239799.

17)Baktash V, HosackT, Patel N, et al. Vitamin D status and outcomes for hospitalised older patients with COVID-19. Postgrad Med J. 2020;0:1-6.

18)Mitchell F. Vitamin-D and COVID-19: do deficient risk a poorer outcome? Lancet Diabetes Endocrinol.2020; 8:570.

19)Ekiz T, Kara M, Ozçakar L. Revisiting vitamin $D$ and home-based exercises for patients with sleep apnea facing the COVID-19 quarantine. J Clin Sleep Med.2020; 16:14091410 .

20)Meltzer DO, Best TJ, Zhang H, et al. Association of Vitamin D Status and Other Clinical Characteristics With COVID-19 Test Results. JAMA Network Open.2020;3:e2019722.

21)Merzon E, Tworowski D, Gorohovski A, et al. Low plasma $25(\mathrm{OH})$ vitamin D level is associated with increased risk of COVID-19 infection: an Israeli population-based study. FEBS J.2020;287:3693-3702.

22)Arvinte $C$, Singh $M$, Mark PE. Serum Levels of Vitamin $C$ and Vitamin D in a Cohort of Critically III COVID-19 Patients of a North American Community Hospital Intensive Care Unit in May 2020: A Pilot Study. Medicine in Drug Discovery 2020; 8: 100064

23)Grant WB, Lahore $H, M c D o n n e l l ~ S L$, et al. Evidence that Vitamin D Supplementation Could Reduce Risk of Influenza and COVID-19 Infections and Deaths. Nutrients.2020;12:988.

24)Omdahl JL, Garry PJ, Hunsaker LA, et al. Nutritional status in a healthy elderly population: vitamin D Am J Clin Nutr.1982; 36:1225-1233.

25)Hovsepian S, Amini M, Aminorroaya A, et al. Prevalence of vitamin $D$ deficiency among adult population of Isfahan City, Iran. J Health Popul Nutr.2011;29:149-155.

26)Biesalski HK Vitamin D deficiency and co-morbidities in COVID-19 patients A fatal relationship? NFS Journal.2020;20:10-21.

27)Lippi G, Hernry BM. Active smoking is not associated with severity of coronavirus disease 2019 (COVID-19) Eur J Intern Med.2020; 75:107-108.

28)Daneshkhah A, Agrawal V, Eshein A, et al. Evidence for possible association of vitamin D status with cytokine storm and unregulated inflammation in COVID-19 patients. Aging Clinical and Experimental Research 2020;32:2141-2158.

29)Daneshkhah A, Agrawal V, Eshein A, et al. The possible role of vitamin D in suppressing cytokine storm and associated mortality in COVID-19 Patients. medRxiv .2020;20058578.

30)Chandran M, Maung AC, Mithal A, et al. Vitamin D in COVID - 19: Dousing the fire or averting the storm? A perspective from the Asia-Pacific. Osteoporosis and Sarcopenia.2020; 6:97-105.

31)Faul JL, Kerley CP, Love B, et al. Vitamin D Deficiency and ARDS after SARS-CoV-2 Infection. Ir. Med. J.2020;113:84.

32)Szeto B, Zucker JE, LaSota ED, et al. Vitamin D Status and COVID-19 Clinical Outcomes in Hospitalized Patients. Endocr Res.2020; 30:1-8.

33)Jain VK, Iyengar $K$, Vaish $A$, et al. Differential mortality in COVID-19 patients from India and western countries. Diabetes Metab Syndr.2020; 14:1037-1041.

34)Laxminarayana R, Wahl B, Dudala SR, et al. Epidemiology and transmission dynamics of COVID-19 in two Indian states. Science.2020;370:691-697.

35)Mohan M, Cherian JJ, Sharma A Exploring links between vitamin D deficiency and COVID-19. PLoS Pathog.2020; 16:e1008874.

36)Khunti $K$, Singh AK, Pareek $M$, et al. Is ethnicity linked to incidence or outcomes of covid-19? BMJ.2020; 369:m1548.

37)Annweiler C, Cao Z, Wu Y, et al. Counter-regulatory "Renin-angiotensin" system-based candidate drugs to treat COVID-19 diseases in SARS-CoV-2-infected patients. Infect Disord Drug Targets.2020;20:407-408. 
38)Novel CPERE. The epidemiological characteristics of an outbreak of 2019 novel coronavirus diseases (COVID-19) in China. Zhonghua Liu Xing Bing Xue Za Zhi.2020;41:145151. 